\title{
Medical Simulation-Based Learning Outcomes in Pre-Clinical Medical Education
}

Maxwell J. Jabaay ${ }^{1}$, Dario A. Marotta ${ }^{1,2}$, Stephen L. Aita ${ }^{3}$, Dianne B. Walker ${ }^{4}$, Leah O. Grcevich ${ }^{1}$, Victor Camba ${ }^{1}$, James R. Nolin ${ }^{4}$, James Lyons ${ }^{5}$, John Giannini Jr. ${ }^{4}$

1. Department of Research, Alabama College of Osteopathic Medicine, Dothan, USA 2. Department of Neurology, Division of Neuropsychology, University of Alabama, Birmingham, USA 3. Department of Psychiatry, Geisel School of Medicine at Dartmouth, Lebanon, USA 4. Department of Simulation, Alabama College of Osteopathic Medicine, Dothan, USA 5. Department of Clinical Sciences, Alabama College of Osteopathic Medicine, Dothan, USA

Corresponding author: Maxwell J. Jabaay, jabaaymj@acom.edu

\section{Abstract}

\section{Introduction}

Medical simulation is widely used in the United States medical curriculum. However, learning outcomes based on simulation have yet to be reported. In this study, we aim to characterize the objective performance of first- and second-year medical students following eight weeks of medical simulation-based learning.

\section{Methods}

First- $(n=25)$ and second-year ( $n=15)$ medical students were recruited for this study. We designed and administered a novel pre-experience examination to collect participant demography and assess simulation and non-simulation knowledge. Following 14 high-fidelity simulation scenarios over the course of eight weeks, we administered an identical post-experience examination and compared performance, primarily using a within-subjects analytic design.

\section{Results}

Student performance improved by an average of $18 \%$ following the medical simulation experience, and firstyear students demonstrated greater benefit (22\%) as compared to second-years (12\%). Relative to first-years, second-year students showed higher overall performance on both pre- and post-examination. Demographic factors and prior medical experience were not significantly associated with assessment performance and score improvement.

\section{Conclusions}

Our data supported the efficacy of simulation-based learning as evidenced by the significant improvement in objective performance on a standardized examination. That is, both first- and second-year medical students demonstrated test-score improvement following an eight-week medical simulation program. Of note, the first-year students exhibited greater benefit (at the group level). Importantly, these findings were

Review began 11/12/2020 Review ended 11/27/2020 Published 12/03/2020

\section{() Copyright 2020}

Jabaay et al. This is an open access article distributed under the terms of the Creative Commons Attribution License CC-BY 4.0., which permits unrestricted use, distribution, and reproduction in any medium, provided the original author and source are credited. statistically unrelated to participant demographic and background variables. Collectively, this study provides preliminary evidence that medical simulation in the pre-clinical phase of undergraduate medical education is an effective tool for student learning.

Categories: Emergency Medicine, Medical Education, Medical Simulation

Keywords: undergraduate, pre-clinical, medical education, usmle, emergency medicine, clinical, comlex

\section{Introduction}

Medical simulation-based learning is a multidisciplinary approach to medical learning by which subject matter experts produce realistic medical scenarios to facilitate learning in a controlled setting [1]. Contemporary simulation encourages active learning, reinforces didactic material, and presents clinically relevant topics as an authentic assessment of medical knowledge [2-4]. Simulation learning also provides an engaging environment in which students can practice high-stress medical decision making without jeopardizing patient safety [5-6]. As such, simulation training provides a pragmatic and affordable way to implement standardized patient-care experiences earlier in a student's medical education [7].

Traditionally, pre-clinical US medical education has been carefully tailored to prepare students for the first round of medical licensing examinations, which are highly correlated to residency placement and largely focus on the fundamentals of biomedical sciences [8-9]. In an unprecedented advance, the United States Medical Licensing Examination (USMLE) Step 1 will transition from a nominal score value to a dichotomous “pass-fail” scoring system beginning in the year 2022. In response to this change, residency program directors report that an increased weight will be placed on the score of USMLE Step 2 exams, which 
emphasize clinical management [10]. Commensurate with this change, we expect to see an earlier introduction of clinical experiences to the medical school curriculum. However, this is problematic given the competition between interprofessional students requiring preceptorships and advances in medical management have led to decreasing lengths of stay in the hospital. As such, there are fewer opportunities for gaining clinical experience than ever before [11]. Therefore, the exploration of simulation modeling into pre-clinical education may provide a viable solution to introducing clinical experience amidst a shortage of qualified clinical preceptorships.

There is an extensive body of literature discussing the effectiveness of low- and high-fidelity simulation in clinical practice to enhance the ecological validity of medical instruction [12-15]. Despite this, there is a paucity of studies directly examining the utility of simulation learning in the pre-clinical phase of medical education. More specifically, the current literature lacks a detailed comparison of simulation learning outcomes between first- and second-year medical students. To address this gap in the literature, we investigated the effects of an eight-week medical simulation experience between first- and second-year medical students. We also chose to evaluate the impact of a student's background (ie., demographics, year in medical school, and past medical experiences) on simulation learning. We predicted that first- and secondyear medical students would benefit, albeit differently, from participation in medical simulation, as assessed by score improvement on a standardized examination. We also hypothesized a relation between past student experiences (medical, educational, and simulation) and examination performance such that these modifying factors would produce greater improvement in post-test scores compared to students without past medical experiences or fewer years in medical school.

\section{Materials And Methods \\ Participants}

A total of 40 medical students at a college of osteopathic medicine located in the southeastern United States, voluntarily participated in an eight-week high-fidelity medical simulation program between September 2019 and November 2019. Participants were limited to first- and second-year medical students. This study was approved by the college's institutional review board (IRB\# HS190820EX). Written consent was obtained separately from each participant prior to the administration of pre- and post-simulation examinations.

\section{Data collection}

Assessment

Within one week from the beginning of the simulation learning experience, participants were administered a 31-question multiple-choice pre-test designed to assess the following: 1) six questions assessing demographic variables; 2 ) eight medically related questions that were not reviewed during the simulation experience (note: these questions served a 'control' function where they were purposely unrelated to the simulation experience to account for/measure artifact score change); 3 ) 16 medically-related questions whose content was taught during the simulation experience, which served as a measure of simulation performance. Test questions were created by study authors based on the specific cases used during the eightweek simulations. Participants were not given feedback or answers to test questions. Scores were deidentified using a two-digit number, which was only known by the participant. This number was used to match pre- and post-test scores for comparison.

Participants were not informed of the existence of the post-test until just before the post-test was administered. A post-test, composed of identical questions as the pre-test, was administered less than one hour after completing the final training case. One medically related, non-simulation question was inadvertently released to participants during a debriefing session (prior to the post-test); consequently, we excluded this item from all analyses. See Appendix A for copies of the pre- and post-simulation examinations.

Simulation Experience

Participants were self-arranged into eight groups of five participants, each of who met weekly for the simulation experience. Each participant was assigned a specific role for each simulation patient encounter (e.g., team captain, scribe, history taker, physical examiner, and case coordinator). Students were allowed to change roles within groups during subsequent encounters.

In each weekly simulation experience, two groups met at the host institution's simulation complex. Participants were not provided any information before each encounter. One group actively participated in an acute care scenario featuring a high-fidelity human patient simulator programmed using simulation software. The remaining group observed the unfolding scenario via live remote audio and video streaming to the debriefing room. The observation group was provided with the same laboratory values and imaging by a second clinical simulation instructor to keep the observation group engaged during the patient encounter. 
During the case, participants were presented with the patient's chief concern, medications, past medical history, family history, and social history to varying degrees of detail. Participants were not given explicit instructions on how to work as a team to obtain relevant history and physical findings. Instead, they were given full autonomy. Participants could obtain the history from the patient or caregiver, perform any physical examinations, order laboratory tests and imaging, perform procedures, administer medication with real-time feedback, and order results pushed to an in-room monitor. Scenarios were programmed to progress through a variety of stages based on ideal management strategies. Each scenario lasted for approximately 15 minutes and was concluded at the discretion of the instructor. Immediately following the scenario, clinical simulation instructors conducted a debriefing session with both participant groups. The debriefing session consisted of an interactive 20-minute discussion summarizing key aspects of the case such as patient presentation, laboratory and imaging findings, and ideal patient management strategies. At the conclusion of the debriefing session, the two participant groups switched roles and experienced a second unrelated encounter. Each team participated in a supplementary voluntary session, which reviewed the capabilities of the high-fidelity simulator, including heart sounds, lung sounds, dysrhythmias, and supplies available in the crash cart; this was an adjunctive experience in which no team practiced an additional vignette.

In total, each group experienced seven encounters via direct participation and seven encounters via observation for a total of 14 experienced simulation cases. A summary of the 14 clinical vignettes is available in Appendix B.

\section{Measures}

The demographic variables - sex, class year (e.g., 1st year, 2nd year), the highest educational level achieved, prior medical experience, and prior competitive simulation experience - were collected as part of the preand post-test examination.

Performance variables: Pre- and post-test scores were used as performance metrics. Data were compiled and entered into Qualtrics computer software, which collated and parsed the data into desired outputs. An independent manual tabulation of data was also conducted to confirm the data was collected and recorded correctly.

SIM score: Sixteen medically related multiple-choice questions associated with simulation cases served as a measure of cohort simulation performance. SIM questions are generally related to the following content areas: basic knowledge, cardiology, case management, neurology pathology, pharmacology, respiratory, and trauma.

Non-SIM score: Eight medically related multiple-choice questions not related to cases covered during the simulation served as a control.

Change score: Differences in the post- and pre-test SIM and non-SIM scores were tabulated to assess a participant's relative change in performance. Separate change variables for the SIM and non-SIM scales were computed as follows: Change $(\Delta)$ Score = Post-Test Score - Pre-Test Score. Accordingly, positive values on change variables reflect score increase while negative values indicate an interval score decrease.

\section{Statistical analysis}

Prior to conducting main analyses, demographic and performance variables were examined for group differences (i.e., between first-year and second-year students) using chi-squared ( $\chi 2)$ tests for categorical variables and independent t-tests for continuous variables. In addition, performance variable distributions were examined for normality (i.e., skewness and kurtosis). Lastly, bivariate correlations were performed to determine whether demographic variables were associated with any of the performance-based outcome variables for the total sample.

For main analyses, paired-samples t-tests were performed on SIM and non-SIM-related questions to evaluate pre-post score differences following the eight-week simulation experience. The analysis was conducted across the total sample as well as within the first- and second-year students (separately) to examine the consistency of the effects. Finally, the degree of test-score change was alternatively assessed using a computed variable of score change for each performance-based variable. Doing so allowed for direct comparison of first- and second-year medical students' score change for SIM and non-SIM-related evaluative questions.

The main measure of effect size for t-tests was Cohen's $d$, with values of $0.2,0.5$, and 0.8 corresponding to small, medium, and large effect sizes, respectively [16]. Additional effect size indices interpreted were Cramér's V $(\varphi c)$ for $\chi 2$ tests and Pearson's $r$ correlation coefficient for bivariate correlations; values were interpreted similarly, where $0.1,0.3$, and 0.5 reflected weak, moderate, and strong associations, respectively [16]. The level of statistical significance ( $\alpha$ ) was set to 0.05 (two-tailed) for all analyses. Participants with missing or improperly completed examinations were excluded from the analyses. The Statistical Package for the Social Sciences (SPSS) program, version 26 (IBM Corp., Armonk, NY) was used for all statistical analyses. 


\section{Cureus}

\section{Results}

\section{Sample characteristics}

Table 1 displays demographic and performance variable descriptive statistics for the final total sample as well as stratified by medical student year. From the original sample of 40 participants, three $(7.5 \%)$ were excluded from data analyses due to missing post-test scores $(n=2,5 \%)$ and having to repeat first-year coursework ( $\mathrm{n}=1,2.5 \%)$. The majority of final samples had attained a bachelor's degree as the highest level of education ( $n=28,75.7 \%)$, were male $(n=25,67.6 \%)$, and were first-year medical students $(n=22,59.5 \%)$ who possessed some level of prior medical experience $(n=28,75.7 \%)$. Overall, prior medical experience consisted mostly of being a prior medical scribe ( $n=16 ; 43 \%)$, followed by nursing assistant $(n=8 ; 22 \%)$, emergency medical technician $(n=4 ; 11 \%)$, nurse or nurse practitioner $(n=2 ; 5 \%)$, and pharmacist $(n=1 ; 3 \%)$. Demographic comparisons between first-year $(\mathrm{n}=22)$ and second-year $(\mathrm{n}=15)$ students revealed no significant difference in gender [63.6\% vs. $73.3 \%$ male; $\chi 2(1, n=37)=0.38, p=.54, \varphi c=.10]$, educational attainment $[72.7 \%$ vs. $80.0 \%$ bachelor's; $\chi 2(2, n=37)=0.78, p=.68, \varphi c=.15]$, and prior history of medical experience $[77.3 \%$ vs. $73.3 \% ; \chi 2(1, \mathrm{n}=37)=0.08, \mathrm{p}=78, \varphi \mathrm{c}=.05]$. 


\section{Cureus}

Variable Type

Demographic Variables

Sex, $n(\%)$

Female

Male

Education Level, n(\%)

Bachelor's Degree

Master's Degree

Doctorate

Past Medical Experience, $n(\%)$

Yes

No

Medical Experience Type, $n(\%)$

Medical Scribe

Emergency Medical Tech

Nurse

16(43.2)

8(21.6)

4(10.8)

1(2.7)

Nurse Practitioner

Pharmacist
${ }_{1}^{\text {st }}$ Year Medical Students (n = 22)

nd Year Medical Students (n = 15)

p (es)*

$\left(\Phi_{c}\right)$

4(26.7)

11(73.3)

14(63.6)

16(72.7)

12(80.0)

$3(20.0)$

$68(.15)$

$0(0.0)$

1(4.5)

17(77.3)

$11(73.3)$

5(22.7)

4(26.7)

6(40.0)

3(20.0)

2(13.3)

1(6.7)

1(6.7)

$0(0.0)$

$1(4.5)$

$11.4(2.4) 71 \%$

$<$

$.001(1.33)$

13.3(1.4) $83 \%$

$.09(0.61)$

1.9(1.9) $12 \%$

$.02(0.82)$

3.9(1.9) $48 \%$

$.66(0.15)$

4.3(1.6) $54 \%$

.05(0.69)

$0.5(1.1) 6 \%$

$.07(0.64)$

\section{TABLE 1: Descriptive statistics for demographic and performance variables}

Note. es=effect size; $p$ values for demographic variables reflect chi-square analyses, and independent t-tests for the test variables; respective effect size statistics shown in parentheses for each set of variables. ${ }^{a}$ SIM refers to simulation-related examination questions exclusively. ${ }^{b}$ Non-SIM refers to non-simulation-related examination questions exclusively. ${ }^{c}$ SIM and non-SIM score change, denoted by " $\Delta$," was computed as [Post-Test Score - Pre-Test Score], where positive values reflect interval increase in test-scores.

\section{Performance variables}

Visual inspection of performance variable distributions as well as skewness and kurtosis statistical tests were not concerning for non-normality. Accordingly, parametric statistical analyses were deemed appropriate. The total evaluation scale (i.e., all 24 items summed) demonstrated acceptable reliability, as measured by internal consistency, for both the pre- and post- administrations (Cronbach's $\alpha=.72$ and .76, respectively). 
Bivariate correlations were carried out to examine relations between demographic/background variables and performance outcome variables in the total sample. Education, gender, and prior medical experience were not significantly correlated with any of the SIM and non-SIM outcome variables. Next, independent t-tests were conducted to examine group differences in each performance variable. Analysis revealed first-year students produced significantly lower SIM pre-test scores $[\mathrm{t}(35)=-4.02, \mathrm{p}<.001, \mathrm{~d}=1.33$ ] and non-SIM posttest scores $[\mathrm{t}(35)=-2.05, \mathrm{p}=.05, \mathrm{~d}=0.69)]$ compared to second-year students. See Table 1 for full descriptive statistical information.

\section{SIM and non-SIM test score change}

Table 1 displays SIM and non-SIM test score changes. Table 2 displays paired-sample t-test findings for preand post-test raw scores for the overall sample as well as by year in medical school. For the overall sample, significant pre-post test score change was observed for SIM [ $t(36)=-7.75, \mathrm{p}<.001, \mathrm{~d}=1.27]$ but not non-SIM $[\mathrm{t}(36)=-0.12, \mathrm{p}=.91, \mathrm{~d}=0.02]$ questions. We then conducted the same within-subjects analysis separately for each medical school year group. For first-year students, SIM test-scores significantly increased over the interval $[\mathrm{t}(21)=-7.38, \mathrm{p}<.001, \mathrm{~d}=1.57]$, but there was no difference between pre- and post-scores on the nonSIM test $[\mathrm{t}(21)=1.16, \mathrm{p}=.26, \mathrm{~d}=0.25]$. Rather, the first-year students showed subtle non-SIM test-score decline following the interval ( $\mathrm{M}$ declined from 3.6 to 3.2). Second-year medical students also showed improvement in SIM test-scores [ $\mathrm{t}(14)=-3.84, \mathrm{p}=.002, \mathrm{~d}=0.99$ ] but not non-SIM [ $\mathrm{t}(14)=-1.61, \mathrm{p}=.13, \mathrm{~d}=0.41]$, following the eight-week simulation experience.

\begin{tabular}{|c|c|c|c|c|c|}
\hline Reference Group & Outcome Variable Pair ${ }^{\text {a,b }}$ & $\mathbf{t}$ & df & $\mathbf{p}$ & d \\
\hline \multirow{2}{*}{ Total Sample } & Pre- vs. Post-SIM Test-Score & -7.75 & 36 & $<.001$ & 1.24 \\
\hline & Pre- vs. Post-Non-SIM Test-Score & 0.12 & 36 & .91 & 0.20 \\
\hline \multirow{2}{*}{ 1st Year Medical Students } & Pre- vs. Post-SIM Test-Score & -7.38 & 21 & $<.001$ & 1.57 \\
\hline & Pre- vs. Post-Non-SIM Test-Score & 1.16 & 21 & .26 & 0.25 \\
\hline \multirow{2}{*}{ 2nd Year Medical Students } & Pre- vs. Post-SIM Test-Score & -3.84 & 14 & .002 & 0.99 \\
\hline & Pre- vs. Post-Non-SIM Test-Score & -1.61 & 14 & .13 & 0.41 \\
\hline
\end{tabular}

TABLE 2: Within-subjects t-test results for the total sample and stratified by medical student year

a SIM refers to simulation-related examination questions exclusively. ${ }^{\text {b }}$ Non-SIM refers to non-simulation-related examination questions exclusively.

Lastly, we investigated whether the degree of performance change differed as a function of the medical student group by way of computing a distinct score change variable for the SIM and non-SIM-related questions. Independent samples t-tests were then performed to compare SIM and non-SIM-related performance changes between first-year and second-year medical students. The analysis revealed a significant difference in score change for SIM-related questions $[\mathrm{t}(35)=2.42, \mathrm{p}=.02, \mathrm{~d}=0.82]$ such that the first-year medical students demonstrated greater interval change in scores $(\mathrm{M}=3.6, \mathrm{SD}=2.3)$ as compared to second-year students $(\mathrm{M}=1.9, \mathrm{SD}=1.9)$. Alternatively, there was no significant group difference in non-SIMrelated question score change $[\mathrm{t}(35)=-1.85, \mathrm{p}=.07, \mathrm{~d}=0.64]$ though the second-year medical students displayed a mild trend of greater score improvement $(\mathrm{M}=0.5, \mathrm{SD}=1.1)$ than the first-years $(\mathrm{M}=-0.4, \mathrm{SD}=1.5)$.

\section{Discussion}

Simulation learning in undergraduate medical education remains understudied, despite its potential role in providing low-risk clinical experiences to medical students. In this study, we used objective pre- and postexamination performance scores to compare first- and second-year medical students following an eightweek medical simulation experience. We found that both first- and second-year students had significant improvements in performance. While student scores improved overall, first-year students were found to have greater performance improvements compared to second-year students. Conversely, there were no significant differences attributed to a participant's sex, education level, or past medical experience on performance. The lack of correlation found between the previously mentioned variables and percent change remained unmodified even after factoring in the student's year in school. Medical students, irrespective of past experiences, demonstrated acquisition of knowledge over the interim period, likely reflecting a significant benefit from simulation learning experiences [17].

On average, medical students showed an improvement in performance of $18 \%$. Performance improvement was twice as high in first-year students (22\%) compared to second-year students (12\%). This suggests highfidelity medical simulation may be an effective learning tool in pre-clinical medical education, especially for 
first-year medical students. That is, the degree of benefit from the simulation experience may be moderated by medical student year, as first-year students benefited more than their second-year counterparts. Generally, students have a greater foundation of knowledge by the second year of medical school. For instance, at the host institution, first-year students had only experienced three months of basic science courses with minimal clinical instruction at the time of the study. Conversely, second-year students had completed system-based clinical courses in multiple body systems. As expected, second-year test performance was higher in both pre- and post- examinations. In a similar vein, a student's year in medical school was positively associated with higher pre-test performance $(r=0.56, p<0.01)$ such that second-year student status was strongly associated with higher pre-test scores. Meanwhile, a similar correlation was not observed with post-test performance. While first-year students scored 19\% lower than second-year students on the pre-test, this deficit was attenuated to $8 \%$ on the post-test. Post-test scores for non-SIM items were not associated with the same degree of improvement but rather, there was a slight decline in scores following the eight-week training. Together, this improvement in first-year students may suggest medical simulation may help students assimilate a broader foundation of knowledge, especially in those who have less experience prior to medical school.

In this study, $76 \%$ of participants had prior medical experience while $24 \%$ had a master's degree or higher. Interestingly, neither of these attributes were associated with better post-test performance. This may be the result of context-dependent factors within the simulation scenarios themselves. For example, acute care settings, such as those simulated in these scenarios, require proficiency in situational awareness, medical decision-making, and overall clinical management to achieve desirable outcomes [18]. It is possible that medical experiences that are not directly related to acute care may not play a functional role in improving simulation-related performance. Similarly, even though a participant's level of education may correlate to higher didactic performance, higher education levels may provide little value without being able to apply acquired knowledge within the confounds of a rapidly evolving medical scenario [19-20]. Since participant characteristics appear to not influence performance outcomes, students of varying backgrounds may find value in simulation learning. This is particularly important in the setting of undergraduate medical education, considering that the diversity of matriculating medical students in the United States has steadily risen over the past 40 years [21].

Several limitations are present in this study. First, this study only examined performance among first- and second-year medical students in the pre-clinical phase of medical education. Therefore, conclusions are not generalizable to third- and fourth-year students. Next, students were given identical pre- and postexaminations eight weeks apart, which introduces possible bias from practice effects. However, threats from this potential bias were remedied by the fact that (a) we analyzed interval change (lack thereof) in nonsimulation based content (which all participants received at pre- and post-test periods), and (b) participants were not informed of the presence of a post-test to avoid recall bias in the form of purposeful memorization of questions and independently sought-out answers. Nevertheless, it remains a possibility that practice effects could have been differentially present in the question sets (e.g., stronger in simulation-related questions). Pertinent to our study, within-subject designs are also susceptible to subject history (i.e., participants having different life experiences across the study period) and maturation effects (i.e., participants differentially maturing over the interval period, which may influence performance. Ordereffects and nonsymmetrical carry-over effects were not a concern by virtue of our study's simulation intervention and identical tasks. Lastly, while an independent control group was not used as a part of the study design, an inherent strength of the within-subjects design is that individual differences are wellcontrolled (as participants act as their own controls).

\section{Conclusions}

The results of this study demonstrate that preclinical medical students show significant improvement in objective performance measures following eight weeks of medical simulation. First-year students benefited most from the simulation experience, as evidenced by the highest change in post-test scores. Additionally, a student's sex, the highest level of education, and prior medical experience had no bearing on performance outcomes. We predict that the changing of the USMLE Step 1 from a scored exam to pass-fail will shift medical education towards emphasizing early clinical contact. In this fluid environment, medical simulation serves to reinforce biomedical concepts and acts both as a teaching strategy as well as a tool to assess clinical competency. Together, this information supports the use of simulation learning in pre-clinical undergraduate medical education.

\section{Appendices}

\section{Appendix A}

Figure 1, Figure 2, and Figure 3 comprise the written assessment that was used as the pre-test and post-test. 


\section{Cureus}

Appendix A: Medical Simulation Examination

1. Anticipated graduation year:

$\begin{array}{ll}\text { a. } & 2022 \\ \text { b. } & 2023\end{array}$

2. Highest level of education

a. Bachelors

$\begin{array}{ll}\text { b. } & \text { Masters } \\ \text { c. } & \text { Doctoral }\end{array}$

3. Past medical/healthcare experience (can choose multiple):

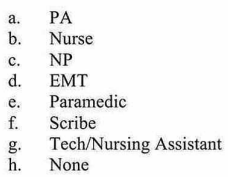

4. What is your biological sex:

a. Male

b. Female
c. Prefer not to disclose

5. Favorite ice cream

$\begin{array}{ll}\text { a. } & \text { Vanilla } \\ \text { b. Chocolate } & \end{array}$

Chocolate
c. Cookies and Cream

d. Strawberry

Birthday cake
Mint Chocolate Ch

geapolitan

g. Neapolitan
h. Rocky Road

Does not like ice cream

6. Have you participated on a simulation competition team in the past?

\section{$\begin{array}{ll}\text { a. } & \text { Yes } \\ \text { b. No } & \text { No }\end{array}$}

7hile you are interviewing a $50 \mathrm{y} / \mathrm{o}$ male patient on the medical-surgical floor, you notice that the patient becomes unresponsive. You feet for a pulse and it is not present. A code con is at in be teliver the highest quality of CPR?

$$
\begin{array}{ll}
\text { a. } & 80-100 \\
\text { b. } & 100-120 \\
\text { c. } & 120-140 \\
\text { d. } & \text { As fast as you can }
\end{array}
$$

8. A $75 \mathrm{y} / \mathrm{o}$ female patient with a history of hypertension and hypercholesterolemia presents to the ER with upper abdomina pain, anxiety and nasea. Upon physical exam, he patient is any immediate life threats?

$\begin{array}{ll}\text { a. } & \text { Blood glucose } \\ \text { b. } & 12 \text { lead EKG } \\ \text { c. } & \text { Complete white blood cell count } \\ \text { d. } & \text { Chest X-ray }\end{array}$

a. Blood glucose

c. Complete whe
9. A 65 y/o male patient with a history of "heart issues" presents to his family practice doctor with a chief complaint of not week, but just has not states hat he got over the flu last episodes of chills and shaking violently at night. Patient vitals are HR 105bpm, RR 24bpm, BP 100/70 $\mathrm{mmHg}$ and a fever of 103.5F. A chest X-ray is performed. What is the diagnosis?

$$
\begin{aligned}
& \text { Pleural effusion of } \mathrm{R} \text { lung } \\
& \text { b. Pulmonary edema } \\
& \text { c. R upper lobe pneumonia } \\
& \text { R Middle lobe pneumonia }
\end{aligned}
$$

$R$ lower lobe pneumonia

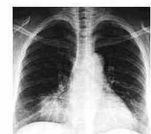

10. A $71 \mathrm{y} / 0$ female patient is at home drinking her morning coffee when all of the sudden she feels weak. EMS rushes the patient to the hospital and calls a stroke alert. Before the
patient is brought to CT what must be ruled out?

$$
\begin{array}{ll}
\text { a. } & \text { Hyperthyroidism } \\
\text { b. } & \text { Hypothyroidism } \\
\text { c. } & \text { Hyperglycemia } \\
\text { d. } & \text { Hypogycemia } \\
\text { e. } & \text { Hyperkalemia } \\
\text { f. } & \text { Hypokalemia }
\end{array}
$$

11. A $75 \mathrm{y} / 0$ male nursing home patient who frequently has breath. Upon physical exam the patient is noted to be using his accessory muscles to breathe and has diffuse wheezing in all quadrants. The patient's vitals are $\mathrm{HR} 120 \mathrm{bpm}, \mathrm{SpO} 283 \%$, BP $130 / 80 \mathrm{mmHg}$. What combination of medications should be administered?

a. IV antibiotics, IM Epinephrine and a beta blocker tics, Albuterol, Ipratropium an

glucocorticoids

IV antibiotics, IV beta blocker, morphine and

glucocorticoids blocker

e. IV antibiotics, IM Epinephrine, Ipratropium and morphine

12. A $45 \mathrm{y} / 0$ male patient is admitted to cardiac ICU after having a massive heart attack. Twenty-four hours later the patient codes and he staff aggressively tres to revive the patient but of the pal and's dhepr?

Arrhythmia leading to asystole

Papillary muscle rupture leading to mitra

regurgitation

Congestive heart failure leading to pulmonary

edema

Interventricular septal rupture leading to shock

e. Dressler syndrome leading to fibrinous pericarditis

13. A $45 \mathrm{y} / \mathrm{o}$ homeless veteran present to the $\mathrm{ER}$ after being found by police in an alley. The patient has slurred speech and ER 15 times in the last 3 moths for similar reasented to the patient is placed in detox for 36 hours what is he at most risk for?
Severe Diarrhea
Seizure
Crushing depressio
Vivid nightmares

FIGURE 1: Written assessment part 1/3 


\section{Cureus}

14. On your internal medicine rotation, you and your rapid patient who has acutely decompensated. What is the first thin you should assess when you get to the patient room?

$$
\begin{array}{ll}
\text { a. } & \text { Circulation } \\
\text { b. } & \text { Breathing } \\
\text { c. } & \text { Airway }
\end{array}
$$

15. A $80 \mathrm{y} / 0$ female presents to the $E R$ due to not acting right and is accompanied by her family. The patient is confused and $h$ sired speech. Upon physical exam, the patient has right normal. The patient is brought to CT (CT scan shown on right). What is the mechanism of action of the best treatment for this patient?

Inhibits Gamma-

Carboxylation of factor

Irreversible block

$\mathrm{P} 2 \mathrm{Y}_{12}$ receptors
Increase conver

plasminogen to plasmin

Increases serum levels of antithrombin

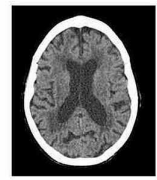

16. While during your internal medicine rotation, you and your rapid response team are called to a $58 \mathrm{y} / \mathrm{o}$ male patient with muscle weakness, fatigue, and EKG changes. The patient's nurse states that the patient has a history of uncontrolled
Diabetes that requires insulin and morning labs showed a GFR of 15 . The EKG is attached what ion is most likely causing the patient EKG and symptoms?

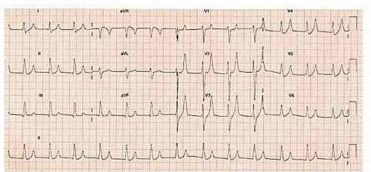

$\begin{array}{ll}\text { a. } & \text { Hypernatremia } \\ \text { b. } & \text { Hyponatremia } \\ \text { c. } & \text { Hyperglycemia } \\ \text { d. } & \text { Hypoglycemia } \\ \text { e. } & \text { Hyperkalemia } \\ \text { f. } & \text { Hypokalemia }\end{array}$

17. A $31 \mathrm{y} / 0$ male was admitted to the to the general medicine floor one week ago. Today the patient presented with a fever and cough that is producing a rust color sputum. What should be ordered on the sputum?

$$
\begin{array}{ll} 
& \text { Viral load } \\
\text { b. Sodium concentration } \\
\text { c. Iron level } \\
\text { d. Bacteria culture } \\
\text { Glucose concentration }
\end{array}
$$

18. While waiting for your SIM case to start, a SIM Fellow brings out a toaster and asks you what is the Glasgow coma scale (GCS) of the toaster?

$$
\begin{array}{ll}
\text { a. } & 15 \\
\text { b. } & 3 \\
\text { c. } & 2 \\
\text { d. } & 1 \\
\text { e. } & 0
\end{array}
$$

19. A 65 y/o male calls 911 due to extreme chest pain. The patient states that the pain came on while watching TV and has not gotten better. Patient vitals are HR 40bpm, BP 100/50mmHg and RR 18bpm. An EKG is preformed and shows STcontradicted in this patient?

$$
\begin{array}{ll}
\text { a. Aspirin } \\
\text { b. IV bolus of normal saline } \\
\text { c. Sublingual Nitro } \\
\text { d. Atropine }
\end{array}
$$

20. A $68 \mathrm{y} / 0$ female fell while she was walking her dog and hit A $68 \mathrm{y} / \%$ female fell while she was walking her dog and hit
her nose on the curb. EMS was called and the patient was her nose on the curb. EMS was called and the patient was
bleeding uncontrollably from the nose. On arrival to the ER the patient's vitals are HR 120bpm, BP 80/50mmHg and RR of $24 \mathrm{bpm}$. The patient is pale, and her entire shirt is wet with blood. EMS brings in the patient's purse filled with medications. What medication is preventing resolution of the epistaxis?

$$
\begin{array}{ll}
\text { a. } & \text { Simvastatin } \\
\text { b. } & \text { Aspirin } \\
\text { c. } & \text { Warfarin } \\
\text { d. } & \text { Metformin } \\
\text { e. } & \text { Insulin }
\end{array}
$$

1. A $21 \mathrm{y} / \mathrm{o}$ construction worker is hit on the upper side of the head (see picture at right) with a steel beam while he was on a job site. He refuses his foreman's offer to be taken to the ER and says he is $O K$. He goes back to work and 3 hours later is for the oigini inur?

$$
\begin{array}{ll}
\text { a. } & \text { Middle cerebral artery } \\
\text { b. Maxillary artery } \\
\text { c. Middle meningeal artery } \\
\text { d. Mental artery } \\
\text { e. Bridging veins } \\
\text { f. Superior sagittal sinus }
\end{array}
$$

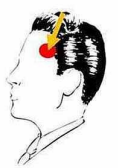

22. A $80 \mathrm{y} / \mathrm{o}$ male presents to the ER with weakness and blood in his stools. The patient is tachycardic and hypotensive. Upon patient is given multiple IV bolus' and rem
What is the next best step in management?

$$
\begin{array}{ll}
\text { a. } & \text { Epinephrine } \\
\text { b. } & \text { O blood } \\
\text { c. } & \text { metoprolol } \\
\text { d. } & \text { Dobutamine }
\end{array}
$$

23. A 23 y/o male patient is brought to the ER by EMS due to decrease mental status. Upon physical exam the patient appears ashy and does not respond to painful stimuli. The patient's respirations are $4 \mathrm{bpm}$ and pinpoint pupils are noted. What medication must be given to this patient?

$$
\begin{array}{ll}
\text { a. } & \text { Naloxone } \\
\text { b. } & \text { Albuterol } \\
\text { c. } & \text { Flumazenil } \\
\text { d. } & \text { Atropine }
\end{array}
$$

24. A 41 y/o male patient presents to the ER with epigastric pain that radiates to the back. The patient is in obvious distress. The patient admits to drinking a bottle of vodka every other day. patient's condition?

a. Glucose
b. Liver function studies Amylase

Partial thrombin time (PTT)

FIGURE 2: Written assessment part 2/3 


\section{Cureus}

25. A $55 \mathrm{y} / 0$ female is brought to the ER after being in a motor vehicle collision. The patient stated that she did not see the car coming from the left. Upon physical exam, the patient has a deep voice, large hands and coarse facial features. Labs show a serum glucose of 200 and the visual field exam shows the following (picture below). What is the signaling pathway of
the hormone that is being over secreted in this patient?

$$
\begin{array}{ll}
\text { a. } & \text { cAMP } \\
\text { b. } & \text { cGMP } \\
\text { c. } & \text { IP } \\
\text { d. } & \text { MAP kinase } \\
\text { e. } & \text { Jak/STAT } \\
\text { f. } &
\end{array}
$$

26. A $31 \mathrm{y} / \mathrm{o}$ male is brought to the ER after being shot multiple times. EMS reports that the patient has lost close to 2 liters of blood and bleeding is not controlled. What should be the fir hing you access and attend to?

a. Airway

b. Breathing
c. Circulation

27. $79 \mathrm{y} / \mathrm{o}$ female patient is brought to the urgent aid clinic by her forgetful and been seeing things that are not there. He also states that these symptoms seem to be waxing and waning over the last 72 hours. The patient medical history includes anxiety of which she recently started taking fluoxetine. The parin Vits inclo $97 \%$ and temp $100.5 \mathrm{~F}$. What is most likely causing the patients psychiatric symptoms?

$$
\begin{array}{ll}
\text { a. } & \text { ETOH withdrawal } \\
\text { b. } & \text { Frontotemporal dementia } \\
\text { c. } & \text { Medication side effect } \\
\text { d. } & \text { Urinary tract infection } \\
\text { e. Hypoxia } \\
\text { f. }
\end{array}
$$

28. A rapid response is called for a $45 \mathrm{y} / \mathrm{o}$ male patient with a weak pulse, EKG rhythm shown below. The patient's blood pressure is $100 / 82 \mathrm{mmHg}$. The patient denies chest pain, shortness of breath and has a GCS of 15 . What is the next be step?

$$
\begin{array}{ll}
\text { a. } & \text { Shock the patient } \\
\text { b. Adenosine } \\
\text { c. Cardiovert } \\
\text { d. Amiodarone } \\
\text { e. Atropine } \\
\text { f. } & \text { Begin CPR }
\end{array}
$$

29. A $50 \mathrm{y} / \mathrm{o}$ male goes into cardiac arrest and during resuscitation he team noticed hat the patient has a polymorphic ventricular . Electrolyte must this patient be given?

$\begin{array}{ll}\text { a. } & \mathrm{Na}^{+} \\ \text {b. } & \mathrm{Mg}^{2} \\ \text { c. } & \mathrm{K}^{2}\end{array}$

$\begin{array}{ll}\text { b. } & \mathrm{Mg}^{2+} \\ \text { c. } & \mathrm{Ca}^{+2} \\ \text { d. } & \mathrm{PO}^{3}\end{array}$

e. $\mathrm{PO}_{4}{ }^{3}$

30. A $67 \mathrm{y} / \mathrm{o}$ female comes into the ER with a headache and blurry vision. The patict $4 \mathrm{bpm}, \mathrm{SpO}_{2} 98 \%$. The include $\mathrm{BP} 220 / 130 \mathrm{mmHg}$, $\mathrm{HR}$ is transferred to the floor. Thirty-six hours later the patient has cardiovase la collapse and dies. During atepsy it is determined via toxicology that the patient died due to the formation of a byproduct from a drug (she had been given or had taken prior to the $E R$ ). The byproduct works by inhibition
of Complex IV of the electron transport chain preventing the formation of new ATP. What drug creates this byproduct that killed the patient?

$\begin{array}{ll}\text { a. } & \text { Cocaine } \\ \text { b. } & \text { Metoprolol } \\ \text { c. } & \text { Nitroprusside } \\ \text { d. } & \text { Hydralazine }\end{array}$$$
\text { e. } \mathrm{PC}
$$

31. A 4-month-old female child is brought to the ER by her arents because of not acting right. The parents stated that this been moving as much she seems to be extra quiet and has not child was very colicky and would frequently cry most of the night. Upon physical exam, the child does not make eye contact and appears ill. Skin finding shown at right. What additional exam finding would most likely be present in this child?

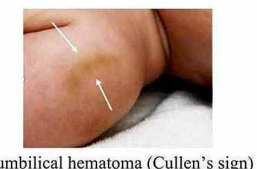

Periumbilical hemato

Passive flexion of neck elicits hip and knee flexion (Brudzinski sign)

Bilateral retinal hemorrhage

Splinter hemorrhages in nail bed

$$
\text { Answers: }
$$

Answers:
7.) B, 8.)B, 9.)D, 10.)D, 11.) B, 12.) A, 13.) C, 14.) C, 15.) C, 16.) E, 17.) D, 18.) B, 19.) C, 20.) C, 21.) C, 22.) B, 23.) A,
24.) D, 25.) E, 26.) C, 27.) D, 28.) C, 29.) B, 30.) C, 31.) D

\section{Reference:}

mage 9: Image source: Case courtesy of Dr Ian Bickle, (https://radiopaedia.org/articles/right-middle-lobeconsolidation?lang=us)

Image 15: Image Source: Case courtesy of Dr Andrew Dixon, adiopediarg rID: 32382

https://radiopaedia.org/cases/elderly-ct-brain?lang=us

Image 16: Image source: Karmacharya P, Poudel DR, Pathak R, Rettew A, Alweis R. 2015. Acute hyperkalemia leading to Community Hosp Intern Med Perspect. 5(3):27993.

Image 21: Clker.com (http://www.clker.com/clipart-man-withno-eye.html)

Image25:https://commons.wikimedia.org/wiki/File:Bitempvf.p g\#ffilelinksUploaded by: Nunh-h

(n)

mage 28: Burns.E. 2019 Ventricular tachycardiamonomorphic VT. Life in the FASTLANE https://litfl.com/ventricular-tachycardia-monomorphic-ecg-

mage 31: Sieswerda-Hoogendoorn T, Boos S, Spivack B, Bilo RA, van Rijin RR. 2011 Educational paper abusive head trauma part I. clinical aspects. J Community Hosp Intwi Med

FIGURE 3: Written assessment part 3/3

\section{Appendix B}




\section{Cureus}

\begin{tabular}{|ll|}
\hline Simulation Scenario & Focus of Simulation Scenario \\
\hline Orientation & Orientation \\
Scenario 1 & Chronic obstructive pulmonary disease exacerbation (COPD) \\
Scenario 2 & Atrial fibrillation \\
Scenario 3 & Pulmonary embolism \\
Scenario 4 & Ischemic stroke \\
Scenario 5 & Neutropenia \\
Scenario 6 & Hypertensive emergency \\
Scenario 7 & Cardiogenic shock \\
Scenario 8 & Serotonin syndrome \\
Scenario 9 & Perforated ulcer \\
Scenario 10 & Subdural hematoma \\
Scenario 11 & Lupus complications \\
Scenario 12 & Endocarditis \\
\hline Scenario 13 & Hypertensive emergency \\
Scenario 14 & Hyperparathyroidism \\
\hline
\end{tabular}

TABLE 3: Simulation scenario summary

\section{Additional Information \\ Disclosures}

Human subjects: Consent was obtained by all participants in this study. Alabama College of Osteopathic Medicine Institutional Review Board issued approval HS190820EX. Animal subjects: All authors have confirmed that this study did not involve animal subjects or tissue. Conflicts of interest: In compliance with the ICMJE uniform disclosure form, all authors declare the following: Payment/services info: All authors have declared that no financial support was received from any organization for the submitted work. Financial relationships: All authors have declared that they have no financial relationships at present or within the previous three years with any organizations that might have an interest in the submitted work. Other relationships: All authors have declared that there are no other relationships or activities that could appear to have influenced the submitted work.

\section{Acknowledgements}

We would like to thank the first- and second-year medical students who participated in this study. We would also like to thank Emmanuel Segui for assistance with statistical interpretations and the Administration at the Alabama College of Osteopathic Medicine for supporting the Simulation Center.

\section{References}

1. Gaba DM: The future vision of simulation in health care . Qual Saf Health Care. 2004, 13:2-10. 10.1136/qhc.13.suppl 1.i2

2. Khan K, Pattison T, Sherwood M: Simulation in medical education. Med Teach. 2011, 33:1-3. 10.3109/0142159X.2010.519412

3. Motola I, Devine LA, Chung HS, Sullivan JE, Issenberg SB: Simulation in healthcare education: a best evidence practical guide. AMEE Guide No. 82. Med Teach. 2013, 35:1511-1530. 10.3109/0142159X.2013.818632

4. Egenberg S, Karlsen B, Massay D, Kimaro H, Bru LE: "No patient should die of PPH just for the lack of training!" Experiences from multi-professional simulation training on postpartum hemorrhage in northern Tanzania: a qualitative study. BMC Med Educ. 2017, 17:119. 10.1186/s12909-017-0957-5

5. Kurup V, Matei V, Ray J: Role of in-situ simulation for training in healthcare: opportunities and challenges . Curr Opin Anaesthesiol. 2017, 30:755-760. 10.1097/ACO.0000000000000514

6. Cavuoto-Petrizzo M, Barilla-LaBarca ML, Lim YS, Jongco AM, Cassara M, Anglim J, Stern JH: Utilization of high-fidelity simulation to address challenges with the basic science immunology education of preclinical medical students. BMC Med Educ. 2019, 19:352. 10.1186/s12909-019-1786-5 
7. Sorensen JL, Ostergaard D, LeBlanc V, Ottesen B, Konge L, Dieckmann P, Van der Vleuten C: Design of simulation-based medical education and advantages and disadvantages of in situ simulation versus off-site simulation. BMC Med Educ. 2017, 17:20. 10.1186/s12909-016-0838-3

8. Gauer JL, Jackson JB: The association of USMLE step 1 and step 2 CK scores with residency match specialty and location. Med Educ Online. 2017, 22:1358579. 10.1080/10872981.2017.1358579

9. Mitsouras K, Dong F, Safaoui MN, Helf SC: Student academic performance factors affecting matching into first-choice residency and competitive specialties. BMC Med Educ. 2019, 19:241. 10.1186/s12909-019-16699

10. Pontell ME, Makhoul AT, Ganesh Kumar N, Drolet BC: The change of USMLE step 1 to pass/fail: perspectives of the surgery program director. J Surg Educ. 2020, [Epub ahead of print]:10.1016/j.jsurg.2020.06.034

11. Cox WJ, Desai GJ: The crisis of clinical education for physicians in training . Mo Med. 2019, 116:389-391.

12. Abrahamson S, Denson JS, Wolf RM: Effectiveness of a simulator in training anesthesiology residents . J Med Educ. 1969, 44:515-519. 10.1097/00001888-196906000-00006

13. Maran NJ, Glavin RJ: Low- to high-fidelity simulation - a continuum of medical education? . Med Educ. 2003, $37: 22-28$.

14. Durham CF, Alden KR: Enhancing patient safety in nursing education through patient simulation. Patient Safety and Quality: An Evidence-Based Handbook for Nurses. Hughes (ed): Agency for Healthcare Research and Quality, Rockville; 2008.

15. Nassif J, Sleiman AK, Nassar AH, Naamani S, Sharara-Chami R: Hybrid simulation in teaching clinical breast examination to medical students. J Cancer Educ. 2019, 34:194-200. 10.1007/s13187-017-1287-3

16. Cohen J: Statistical Power Analysis for the Behavioral Sciences. Routledge Academic, New York; 1988.

17. Knowles MS, Holton EF, Swanson RA: The Adult Learner. The Definitive Classic in Adult Education and Human Resource Development. Routlege Academic, New York; 2015.

18. Rosenman ED, Branzetti JB, Fernandez R: Assessing team leadership in emergency medicine: the milestones and beyond. J Grad Med Educ. 2016, 8:332-340. 10.4300/JGME-D-15-00400.1

19. Fredieu JR, Snyder CW: Positive impact of a master of science in applied anatomy program on USMLE step 1 performance. Anat Sci Educ. 2015, 8:31-36. 10.1002/ase.1455

20. Hammond J: Simulation in critical care and trauma education and training . Curr Opin Crit Care. 2004, 10:325-329. 10.1097/01.ccx.0000140950.47361.c9

21. Applicants, matriculants, enrollment, and graduates to U.S. medical schools . (2020). Accessed: April 3, 2020: https://www.aamc.org/data-reports/students-residents/interactive-data/2019-facts-applicants-andmatriculants-data. 